\title{
WATCH IT
}

Roger Marois*

MAROIS, R. Watch it. Rev. do Museu de Arqueologia e Etnologia. S. Paulo, 2:3-5, 1992.

RESUMO: Os participantes do National Symposium for the Development of Database Standards for Archaeological Collections Management, ocorrido em 1987, na cidade de Fayetteville, Arkansas, descobriram que a partir dos princípios de organização elaborados para cada programação institucional, torna-se impossivel fazer um único programa nacional. Além disso, este artigo apresenta exemplos para demonstrar a necessidade de definir os termos arqueológicos especializados com maior precisão.

UNITERMOS: Metodologia arqueológica. Terminologia. Classificação.

During the 1987 National Symposium for the Development of Database Standards for Archaeological Collections Management held in Fayetteville, Arkansas, participants attempted to standardize databases already operational in various institutions. It was agreed that standardizing would result in enhancing research capabilities, greatly improving efficiency and communications, while eliminating duplication of efforts. However, organizational principles for each database prevented readily identifying commonalties. In the hope of making databases more compatible, it was recommended to put together a series of papers on various topics for the next symposium. One topic concerned the influence of languages on databases, particularly English, French, Porguguese and Spanish.

To study the possible influence of each language on the others would represent a major undertaking and would not necessarily be rewarding, as most participants of the National Symposium were not familiar with any of these languages but English. It was there-

(*) Canadian Museum of Civilization. fore considered more practical to attempt identifying the roots of some computerizing problems which were not included in the other papers. One problem was to define specialized terms used in archaeology.

There is no doubt that people computerizing collections for management or research purposes are confronted not only with problems inherited from previous generations but also with a range of definitions for words that archaeologists regularly work out for themselves, tailoring their systems, like a suit, for their individual needs. At a recent meeting on Lithic Technology held in Austin, Texas, organized jointly with the Archaeology Work Group, (Panamerican Institute of Geography and History), and the Texas Archaeological Research Laboratory (University of Texas), the participants unanimously recognized that the vocabulary at our disposal for describing and identifying artifacts, shapes and manufacturing processes needs defining.

Given that, without definitions, a) terms tend to be used loosely; b) communication lacks clarity and c) the supposedly logical development of analysis suffers from inconsistencies, this paper will provide examples 
to demonstrate the need to define specialized archaeological terms with increased accuracy. From the two industries, lithic and ceramic, that produced most of the artifacts in prehistory, our examples will concentrate on the ceramic.

In ceramic analysis, the most widely used concept is that of "decoration technique". In spite of the common usage of this term, it is surprising to note that a definition is not easily found for it. To determine the meaning of "decoration technique" in each language, one requires examining the definitions of specific decoration techniques in order to extract the elements that seem to be included under "decoration technique". The comparative study of English, French, Spanish and Portuguese terms related to prehistoric ceramic decoration techniques that was published a few years ago, constitutes a good survey of definitions related to specific decoration techniques in four languages and the difficulties involved in extracting the relevant information. It is not sure that such studies are entirely convincing as many people are strongly attached to the belief that tool and motion cannot be separated in a decoration technique. It is obvious that tool, motion and the alteration resulting from the interplay of the tool and the motion, are very closely related to each other. It is also obvious that definitions and classifications take these three variables into consideration.

The following observations can be added to the examples given in the previously mentioned articles. In one computerizing system, the section on "Pottery Surface Treatment/Decoration Technique" includes: incising/engraving, punctations, stamping, impressions and brushing. The wording for these five classes is not consistent as three: incising/engraving, stamping and brushing, refer to a motion while two: punctations and impressions, refer to alterations. One can presume that what is meant is "punctating" and "impressing" but it remains that the wording, being inaccurate, betrays inconsistency. Furthermore, "incising/engraving" are linked together most likely on account of the wet/dry state of the pot when the motion takes place. However, while "pushing or pulling a more or less pointed tool" charac- terizes "incising/engraving", "dragging" characterizes "brushing". As "pushing or pulling" are almost the same as "dragging", the tool not the motion distinguishes respectively "incising/engraving" from "brushing".

The same observations are applicable to "punctations" (or punctating), "stamping" and "impressed" (or impressing). As these three techniques have the same motion in common, it was therefore thought that the system intended to determine classes on the basis of motion and subclasses on the basis of tools, but this does not seem to be the case. "Punctations" included subsclasses distinguished by the tool shape (pointed, round) or the alterations aspect (hemiconical, annular), the tool or the instrument size and the motion (stab and drag for linear punctate. As the point of reference point plays musical chairs with motion, tool and alteration, the compiled frequencies represent a mixture of them and throws a cloud on the meaning or the interpretation. So much for those who are convinced that tool and motion are inseparable.

Moreover, for some people, "trailing" involves pulling or pushing the point or corner of a tool across the wet surface of the clay" while "dragging involves impressing the tool edge into the surface of the vessel at an angle, dragging it slightly, and impressing again." These motions do not correspond to those indicated above. "Trailing" and "incising/ engraving" are not too far apart, but "dragging" has two different meanings.

The following classification of decorative arrangements is another example of inconsistency:

1) Simple collar motif;

2) Opposed collar motif;

3) Crossed collar motif;

4) Hatched collar motif;

5) Horizontal collar motif;

6) Complex collar motif;

7) Interrupted collar motif.

These sub-giroup designations are certainly not coherent as far as nomenclature is concerned. "Simple" should normally be opposed to "complex", forming two general groups subdivided on the basis of their simplicity or complexity. However from the seven groups above, two are respectively designated "sim- 
ple" and "complex", which would imply that the other five groups are neither simple nor complex. These decoration groups are not designated according to any logical or coherent principles that would reflect the criteria the author meant to follow in order to classify the decorative arrangements.

In another decoration system, it is mentioned that:

Class A included all pottery with rectilinear incised designs composed of diagonally opposed lines, diagonal lines or vertical lines.

Class B included all pottery with rectilinear or curvilinear designs that are placed horizontally on the vessel and are composed of horizontal lines. Punctations may appear in these designs but only as minor elements.

In this class descriptions, the terms "design" and "diagonal" should be defined for the reader to determine whether or not design is equivalent to the whole arrangement and whether or not diagonal is synonymous with oblique. Moreover, designs are incised in Class A but nothing about it is mentioned in Class B. Furthermore, if "Punctations appear as minor elements", how can one identify a "minor element" from "a major element" in order to judge whether or not patterns from one class overlap with patterns from another class?

It seems ironical that computerizing will force professional archaeologists to question their long established methods and to reexamine the basis for their deductions and interpretations. If people are unable to solve most of the problems in computerizing archaeological data, it is mainly because professional archaeologists have neglected to clarify their concepts and have not reexamined the fundamentals of their trade on the basis of empirical data. Even if most archaeologists feel insulted when their skills in nomenclature, classification and terminology are questioned, it remains that sooner or later common definitions for objects, shapes, morphological parts and technical terms related to stone, bone and ceramic industries will have to be worked out and style, made less confusing. These are some of the basic conditions which will permit archaeology to approximate the methods of a sound science rather than science-fiction. Watch it.

The examples were choosen at random. References were omitted in order not to give the impression that the author had a bone to pick with someone and to avoid negative comparisons. The identity of the authors is irrelevant to the purpose of this article.

MAROIS, R. Watch it. Rev. do Museu de Arqueologia e Enologia. S. Paulo, 2:3-5, 1992.

ABSTRACT: The participants of the 1987 National Symposium for the Development of Database Standards for Archaeological Collections Management held in Fayetteville, Arkansas, discovered that organizational principles for each database made it impossible to make a single national database out of them. Consultations on standards should be included in the planing process of a national database. Furthermore, this article provides examples to demonstrate the need to define specialized archaeological terms with increased accuracy.

UNITERMS: Archaeological methodology. Terminology. Classification. 